\title{
Direct and Indirect Laryngoscopy: Equipment and Techniques
}

\author{
Stephen R Collins MD
}

\author{
Introduction \\ History and Development of Laryngoscopy \\ Patient Evaluation \\ Predictors of the Difficult Airway \\ Direct Laryngoscopy \\ Approach \\ Patient Positioning \\ Techniques \\ Laryngoscope Blades \\ Indirect Laryngoscopy \\ Optical Stylets \\ Rigid Fiberoptic Laryngoscopes \\ Rigid Video Laryngoscopes \\ Summary
}

\begin{abstract}
Visualization of the larynx by direct or indirect means is referred to as laryngoscopy and is the principal aim during airway management for passage of a tracheal tube. This paper presents a brief background regarding the development and practice of laryngoscopy and examines the equipment and techniques for both direct and indirect methods. Patient evaluation during the airway examination is discussed, as are predictors for difficult intubation. Laryngoscope blade design, newer intubating techniques, and a variety of indirect laryngoscopic technologies are reviewed, as is the learning curve for these techniques and devices. Key words: airway management; laryngoscopy; direct and indirect; airway assessment. [Respir Care 2014;59(6):850-864. (C) 2014 Daedalus Enterprises]
\end{abstract}

\section{Introduction}

Laryngoscopy is a term describing visualization or examination of the larynx by distraction of the upper airway structures, typically for the purpose of tracheal intubation and airway management in modern anesthesia and critical care practice as well as in many trauma scenarios. For

The author is affiliated with the Department of Anesthesiology, University of Virginia School of Medicine, Charlottesville, Virginia.

The author has disclosed no conflicts of interest.

Dr Collins presented a version of this paper at the 52nd RESPIRATORY CARE Journal Conference, "Adult Artificial Airways and Airway Adjuncts," held June 14 and 15, 2013, in St Petersburg, Florida. nearly a century, direct laryngoscopy has been the standard technique for tracheal intubation. In this approach, a rigid laryngoscope is used to expose the laryngeal inlet under direct vision or line of sight to facilitate placement of a tracheal tube beyond the vocal cords. Alternatively, indirect techniques for tracheal intubation have been developed that do not require direct vocal cord visualization. These newer approaches include the design and use of malleable or rigid optical stylets, rigid indirect laryngo-

\footnotetext{
Correspondence: Stephen R Collins MD, Department of Anesthesiology, University of Virginia School of Medicine, Box 800710, Charlottesville, VA 22908. E-mail: src2f@virginia.edu.
}

DOI: $10.4187 /$ respcare. 03033 


\section{DIRECT AND INDIRECT LARYNGOSCOPY}

scopes such as the Bullard and TruView EVO2, fiberoptic technology, and video laryngoscopes, in which video camera systems provide a focused view of the laryngeal inlet. Each of these techniques has distinct advantages and disadvantages, and each is discussed in detail in this review. The flexible fiberoptic bronchoscope and intubation techniques using this device are discussed in a separate review in this issue of Respiratory CARE.

\section{History and Development of Laryngoscopy}

In the 19th century, indirect laryngoscopic techniques were developed that used various lights and mirrors to examine the larynx. ${ }^{1}$ The German physician Bozzini described the first laryngoscope in 1805 , although it was not until 1852 that the first surgical procedure was reported using the technique of direct laryngoscopy, in which a laryngeal polyp was excised..$^{2}$ Since its introduction as a method for tracheal intubation in $1913^{3}$ and blade modifications by Miller ${ }^{4}$ and Macintosh ${ }^{5}$ in the 1940s, direct laryngoscopy has been the conventional technique and accepted standard for tracheal intubation, with success rates that may equal or exceed $99 \%$ in elective or emergency settings. ${ }^{6-8}$

Numerous laryngoscope blades have since been developed with a variety of modifications and improvements. Technological advances include improved illumination with brighter light sources and fiberoptic light transmission. Despite inherent limitations of the direct line-of-sight approach and the emergence and use of various newer technologies for intubation such as rigid indirect laryngoscopes, flexible fiberoptic bronchoscopes, and video laryngoscopes, traditional direct laryngoscopic techniques remain fundamental in the practice of airway management and intubation. This may be due to the simplicity of direct laryngoscopy compared with newer technologies. In addition to very high success rates with the approach, other advantages include robust and portable equipment with relatively low cost and widespread availability as well as unparalleled speed with proper technique.

\section{Patient Evaluation}

Direct laryngoscopy is the most commonly used technique for tracheal intubation as part of general anesthesia or during resuscitation efforts. Review of a patient's pertinent history, as well as general physical examination and specific airway-related assessment, allows the practitioner to prepare for an airway management strategy. Particular urgent or emergent situations may preclude a complete and rigorous airway assessment. Nonetheless, identification of key airway features and anatomic variations, as well as recognition of predictors of a potentially difficult intubation, is paramount in the airway assessment of any patient prior to airway management. The importance of preparation is highlighted by the American Society of Anesthesiologists' "Practice Guidelines for Management of the Difficult Airway," "9 which defines a detailed approach to primary and alternative strategies in airway management before induction of general anesthesia. This stepwise decision-making process includes assessing the need for airway control, the potential for difficult laryngoscopy, the capacity for supralaryngeal ventilation, the risk of aspiration, and the ability of a patient to tolerate apnea.

When intubation is planned, several key anatomical factors influence or determine successful laryngoscopy. These are a patient's glossopharyngeal proportion (tongue-pharyngeal volume proportion), the upper airway or the space above the laryngeal inlet, and the alignment of a visualization vector from the laryngoscopist's eye to the vocal cords. Greenland ${ }^{10}$ recently described a structured overview of preoperative airway assessment in this regard by categorizing these anatomical factors into 3 columns: the anterior column, which comprises volume and compliance of the submandibular space (glossopharyngeal proportion); the middle column, which assesses any obstruction to airway passage (upper airway); and the posterior column, which evaluates a patient's neck range of motion, especially extension of the occipito-atlanto-axial complex. For example, clinical features that affect glossopharyngeal proportion include macroglossia, seen in obesity and obstructive sleep apnea, ${ }^{11}$ as well as retrognathia or scarring from surgery, burns, or radiation therapy to the submandibular area.

Anatomical factors that affect access to a patient's upper airway or preclude laryngoscope blade placement or manipulation include limitations in a patient's mouth opening and intra-oral tumors. Those that affect the visualization vector include poor head extension (eg, patients with short thick necks) and dentition (prominent upper incisors).

\section{Predictors of the Difficult Airway}

A variety of clinical tests and models have been described to predict difficult laryngoscopy and difficult intubation. Most prediction models describe difficult laryngoscopy based on Cormack-Lehane laryngoscopic views, ${ }^{12}$ in which 4 grades are classified (Fig. 1) based on the view obtained at laryngoscopy: grade I, the glottis is completely visible; grade II, only the posterior commissure is visible; grade III, only the tip of the epiglottis is visible; and grade IV, no glottic structures are visible. Higher CormackLehane views (grades III and IV) are associated with difficult intubation. Whereas difficult tracheal intubation is uncommon (incidence of 1-3\%, based on varying definitions used in the literature $\left.{ }^{13}\right)$, the inability to view the 

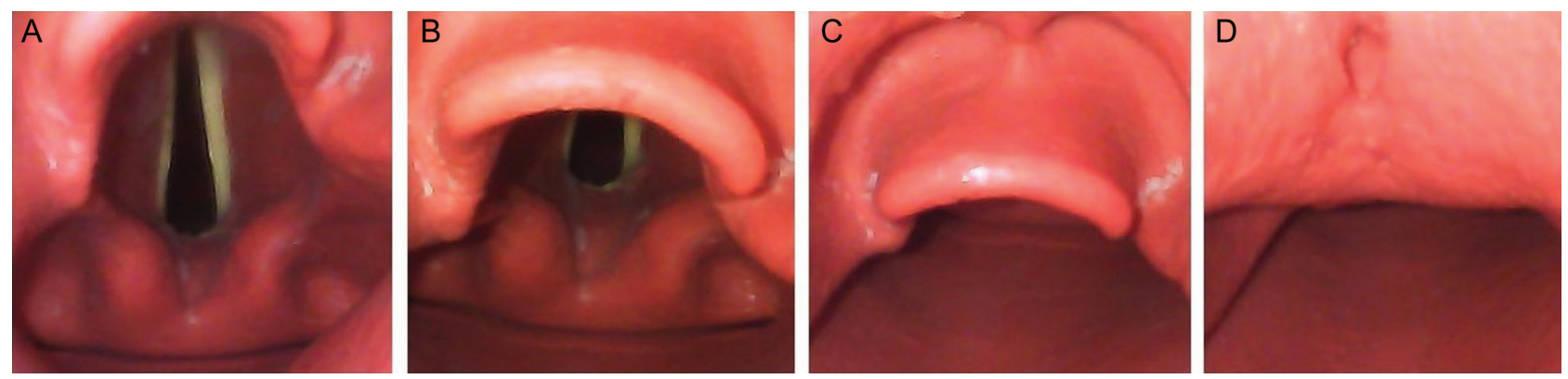

Fig. 1. Laryngoscopic view grading system as initially developed by Cormack and Lehane. ${ }^{12} \mathrm{~A}$ : Grade I, the glottis is completely visible. B: Grade II, only the posterior commissure or posterior portion of the laryngeal aperture is visible. C: Grade III, only the epiglottis is visible. D: Grade IV, no glottic structures are visible, only the soft palate.

larynx during direct laryngoscopy may be as high as $6 \%$ in adult patients. ${ }^{14}$

Multiple studies have attempted to identify qualitative or quantitative measures of the airway examination that predict difficulty or ease of intubation. Findings that suggest difficult airway management include limited mouth opening, short thyromental distance $(<6 \mathrm{~cm})$, prominent or protruding maxillary incisors, and limited neck extension. Given the low positive predictive value of these predictive screening tests, however, their usefulness has been questioned. ${ }^{15}$ Their limitations include a high incidence of false-positive and false-negative results and the fact that they do not address lower airway problems.

One of the most commonly used qualitative assessments in the airway examination measures tongue-pharyngeal volume disproportion. Termed the modified Mallampati classification, ${ }^{16}$ this examination correlates tongue size to pharyngeal size. To perform this bedside test, the patient assumes a seated position with his head in a neutral position, mouth wide open, and tongue protruding to its maximum. This 4-category classification is assigned according to the degree that the base of the tongue masks visibility of pharyngeal structures: class 1, visualization of the soft palate and uvula; class 2, visualization of the soft palate and tonsillar pillars; class 3, visualization of the soft palate only; and class 4, visualization of the hard palate only. The predictive value of this test is improved if the patient extends his neck at the craniocervical junction. ${ }^{17}$ Although one meta-analysis of 42 studies $^{18}$ has shown that the test is not a useful predictor of a difficult intubation when used alone, its utility is improved when part of a comprehensive evaluation that includes assessment of dentition, thyromental distance, and neck extension.

Measures of a visualization vector to align the oropharyngeal axis during direct laryngoscopy include mouth opening, mandibular protrusion, thyromental distance, and neck mobility. Anatomical alterations of these clinical features may limit the direct line of sight for successful direct laryngoscopy and tracheal intubation. Limited mouth opening $(<4 \mathrm{~cm})$ or shortened thyromental distance $(<6 \mathrm{~cm})$ may predict difficulty with laryngoscopy. Mandibular protrusion is tested with the upper lip bite test by asking the patient to protrude the jaw forward to bite the upper lip; this maneuver tests for a more forward position of the lower incisors in relation to the upper incisors and has been reported as an adequate predictor for difficult intubation when used as a single test. ${ }^{19}$ The assessment of neck mobility focuses on the patient's ability to assume the sniffing position.

Due to limitations of any single predictive test and poor discriminative power when used alone, some researchers have evaluated multiple physical features and factors as predictors of difficult laryngoscopy or intubation. One such quantitative measure is the intubation difficulty scale, ${ }^{20}$ used to evaluate intubating conditions and techniques in predicting difficult intubation. Another is the multivariate airway risk index developed by el-Ganzouri et al, ${ }^{21}$ which identifies 7 independent predictors of difficult intubation: limited mouth opening, reduced thyromental distance, Mallampati class 3, reduced neck mobility, inability to prognath, body weight $>110 \mathrm{~kg}$, and history of difficult tracheal intubation. Combining predictors has greatly reduced the false-negative rate and improved predicting difficult laryngoscopic visualization.

\section{Direct Laryngoscopy}

\section{Approach}

Regardless of the type of laryngoscope blade used during direct laryngoscopy, the approach relies on a direct and unimpaired line of sight from the eye of the laryngoscopist to the patient's tracheal opening or glottic opening. The true vocal cords or vocal ligaments are distinctive white bands that border the glottic opening. Together, the vocal cords and glottic opening have a triangular appearance during direct laryngoscopy due to the upward force applied by the laryngoscope blade (Fig. 2). Of importance, the vocal cords meet at the top of the glottic opening and 


\section{DIRECT AND INDIRECT LARYNGOSCOPY}

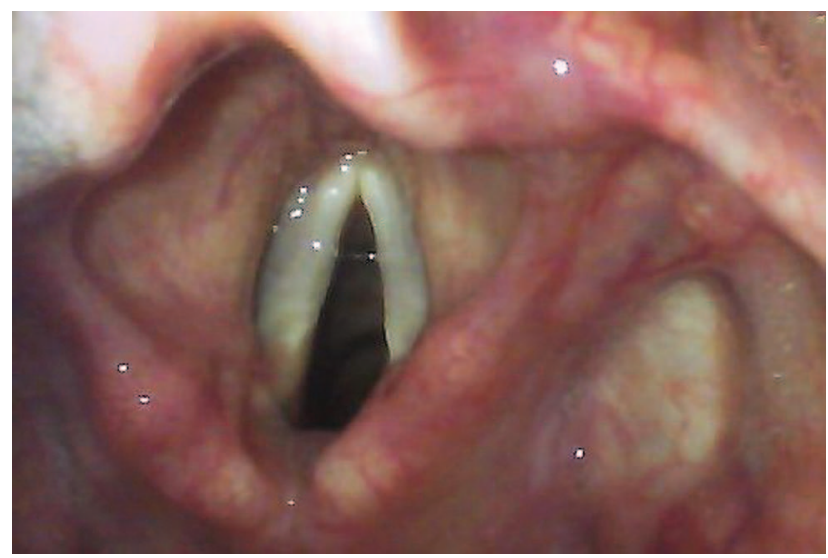

Fig. 2. A view by direct laryngoscopy of the glottic opening, which reveals the true vocal cords. The arytenoids (paired cuneiform and corniculate cartilages) are inferior and anterior to the position of the cords.

are attached anteriorly to the thyroid cartilage. External laryngeal manipulation can displace the vocal cords posteriorly and improve the laryngoscopist's view of the glottic opening during laryngoscopy. This is a trial-and-error process and can be performed solely by an assistant under direction of the laryngoscopist or, alternatively, by the laryngoscopist with the free hand and the subsequent view held by an assistant (bimanual laryngoscopy). Some specific maneuvers have been described that result in improved laryngeal views. In the BURP technique (Backward Upward Rightward Pressure), posterior laryngeal pressure against the cervical vertebrae is applied with superior and (rightward) lateral pressure and has been described with success in some studies. ${ }^{22,23}$ In another study, the BURP maneuver worsened the laryngeal view during laryngoscopy, but the bimanual approach improved it. ${ }^{24}$

Conceptually, direct laryngoscopy can be thought of as progressive visualization of intra-oral and pharyngeal soft tissue structures as the laryngoscope blade is advanced and landmarks are exposed. The laryngoscope blade functions as both a retractor and an illuminator during this process. At the base of the tongue, the epiglottis overlies the laryngeal inlet and is suspended at its base by the hyoepiglottic ligament and the hyoid bone. With a curved laryngoscope blade, the pressure of its distal end against the hyoepiglottic ligament elevates the epiglottis to expose the glottic opening. With a straight blade, the distal end is passed so that the tip lies beneath the epiglottis, which is then lifted to expose the glottic opening. The direction of the lifting force should be along the axis of the laryngoscope handle (ie, parallel to the handle) to avoid using the laryngoscope blade as a lever and potentially damaging upper teeth or other structures.

\section{Patient Positioning}

The sniffing position has traditionally been considered the optimal head position for direct laryngoscopy, with alignment of 3 axes (the oropharyngeal, pharyngeal, and laryngeal) as the anatomical basis for the position (Fig. 3). The head is extended at the atlanto-occipital joint (standard definition of $15^{\circ}$ ), with the neck flexed $35^{\circ}$ for aligning a visual axis from the oropharynx to the glottis. The position is contraindicated in patients with known or suspected cervical spine injury, in which case laryngoscopy can be performed using manual in-line cervical stabilization with an assistant.

The use of proper sniffing position for direct laryngoscopy has been a hallmark of airway management and intubation for decades since its first description in 193626; however, its anatomical basis has recently been challenged, ${ }^{27,28}$ with one study ${ }^{29}$ reporting no significant advantage in the sniffing position compared with simple head extension except in obese patients or those with limited head extension. Similar findings have been reported in obese patients when head elevation with alignment of the patient's sternal notch and external auditory meatus in a horizontal plane may be superior to the sniffing position in this patient population (Fig. 4). ${ }^{30}$ One recent review ${ }^{31}$ summarizes these points and also highlights some of the commercially available elevation pillows for positioning of obese patients for direct laryngoscopy.

\section{Techniques}

During direct laryngoscopy, the laryngoscope blade is typically inserted with the left hand into the right side of the patient's mouth with leftward tongue retraction. Prior to blade insertion, the mouth of an unconscious or anesthetized patient can be opened with a scissors technique accomplished using the thumb and index finger of the right hand (Fig. 5). Initial blade insertion is from the left side as the mouth is scissored open, and the blade is then directed initially from left to right to position the blade flange ultimately toward the left side of the patient's mouth on complete insertion of the blade (Fig. 6). The blade is advanced carefully and directed in a midline approach until the epiglottis is visualized. After the soft palate tissue and tongue are lifted in a direction along the axis of the laryngoscope handle and the glottic opening is exposed, a tracheal tube can be inserted using the right hand and advanced from the right corner of the patient's mouth and through the vocal cords.

Alternative techniques are the paraglossal ${ }^{32}$ and retromolar ${ }^{33}$ approaches that have been suggested for difficult direct laryngoscopies. These are traditionally described using a straight blade laryngoscope that is introduced from the right side. In the paraglossal approach, the laryngo- 


\section{DiRECT AND INDIRECT LARYNGOSCOPY}

A

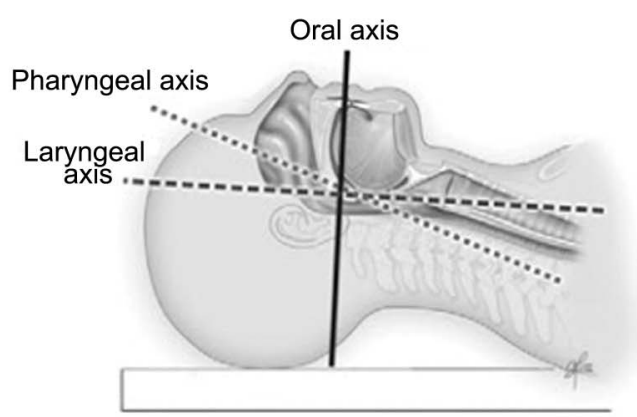

B

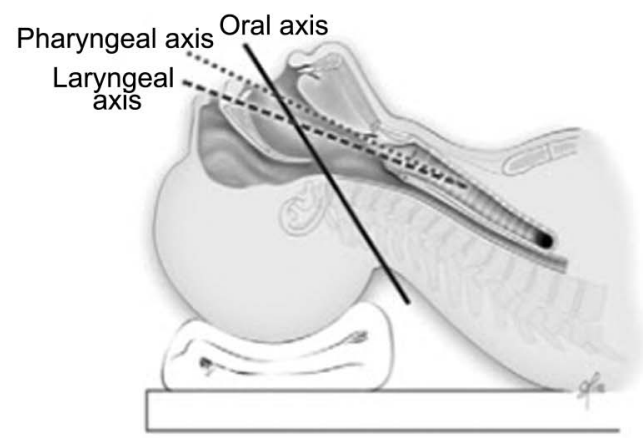

Fig. 3. Classic sniffing position or optimal head position for direct laryngoscopy and the 3-axes alignment theory. The oral axis is defined as a line drawn horizontally across the top of the tongue. The pharyngeal axis is a line tangential from the uvula to the posterior surface of the epiglottis. A: The laryngeal axis is a line drawn at a right angle to the vocal cords. B: Head extension at the atlanto-occipital joint more closely aligns the oral axis with these 2 axes. From Reference 25, with permission.

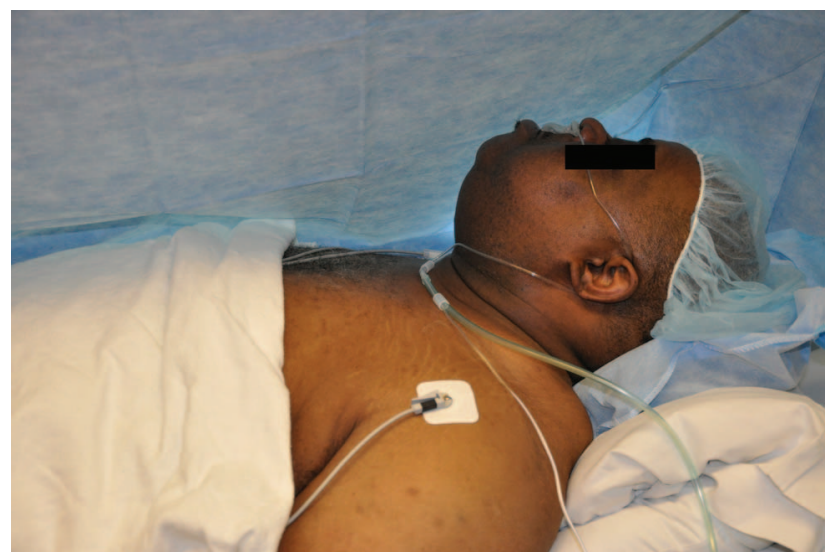

Fig. 4. A morbidly obese patient with optimal head position for airway management/laryngoscopy. With the patient's head supported and shoulders elevated, an imaginary horizontal line can be drawn from the patient's external auditory meatus to the sternal notch.

scope blade is placed beside the tongue but off midline, and the tip is angled medially with anterior force applied as the blade is advanced posterior to the epiglottis. This technique may be useful when the soft palate or tongue cannot be easily displaced, such as in patients with intraoral lesions or macroglossia. ${ }^{34}$ In retromolar laryngoscopy (a modification of the paraglossal approach), the patient's head is turned to the left, and the laryngoscope blade is kept over the patient's molars in an attempt to improve the laryngoscopic view. This may be particularly useful when midline structures impede the laryngeal view. ${ }^{35} \mathrm{~A}$ leftsided method has also been described. ${ }^{36}$

\section{Laryngoscope Blades}

A laryngoscope is composed of a handle and a blade that contains a light source. Improved illumination with

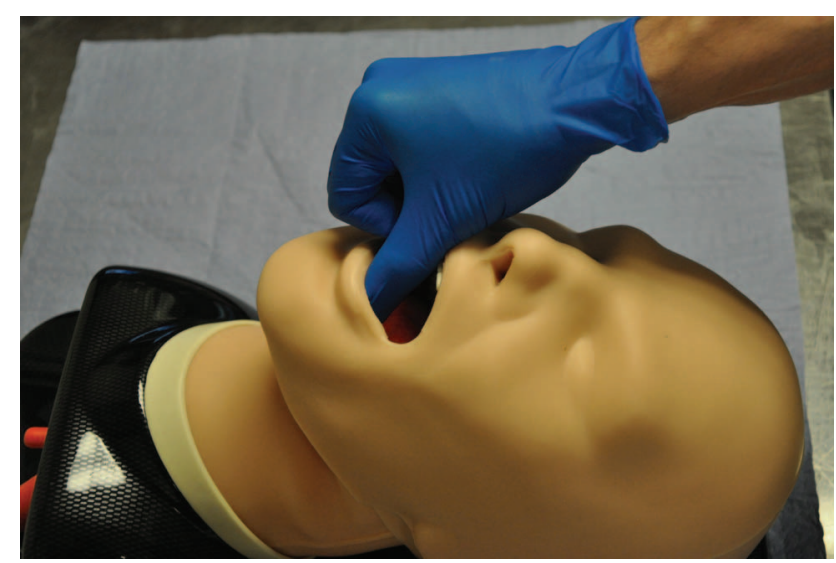

Fig. 5. Mouth opening using the scissors technique. This is accomplished by placing the thumb on the lower teeth and the index finger on the upper teeth.

light-emitting diodes or fiberoptic light transmission has replaced incandescent bulb technology in recent years, improving laryngoscope design. The laryngoscope blade itself consists of 3 components: a spatula, which passes over the lingual surface of the tongue; a flange, which is used to direct or displace the tongue; and a tip, which is designed to lift the epiglottis either directly or indirectly (Fig. 7).

A multitude of laryngoscope blades have been designed. ${ }^{37}$ A representative list is shown in Table 1, which highlights some of the characteristics and advantages of various types of curved and straight blades. I refer the reader to a recently published book chapter ${ }^{38}$ for images and further descriptions of various laryngoscope blades. In summary, 2 basic blade designs dominate: curved blades exemplified by the standard Macintosh design and straight blades such as the common Miller blade. The large flange of the Macintosh is designed for tongue displacement, and the curved blade is designed to elevate the epiglottis indirectly. Like other straight blades, the Miller blade is de- 


\section{DIRECT AND INDIRECT LARYNGOSCOPY}

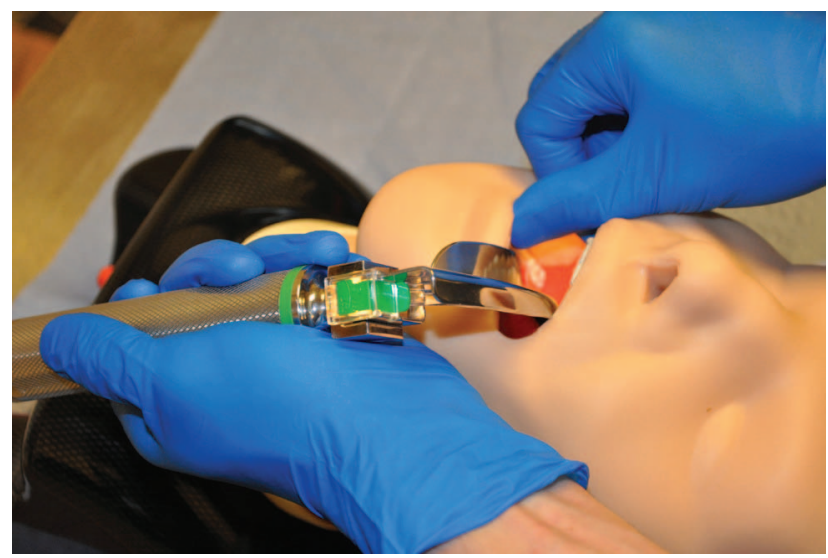

Fig. 6. With the patient's mouth opened, the tip of the curved blade (Macintosh) is inserted into the right side of the mouth. By rotating the wrist, the tongue can then be displaced (to the patient's left) with the flange of the blade. The larger flange of the curved Macintosh blade allows for easier tongue displacement than traditional straight blades.

signed to lift the epiglottis directly and is particularly useful if a large, floppy, or irregularly shaped epiglottis is encountered during laryngoscopy. These are available with variously sized blades and handles (standard, pediatric, or short) to accommodate patient size, anatomic characteristics, and operator preference (Fig. 8). In general, straight blade designs as defined by the dimensions of their spatula and flange have smaller displacement volumes and are favored in patients with smaller displacement space (eg, children or patients with micrognathia, prominent upper incisors, or short mental-hyoid distance). Curved blades like the Macintosh may be favored for tongue control or ease of intubation. In at least one study, the Miller blade's profile was found to provide a better view of laryngeal structures, but the Macintosh blade facilitated speed and ease of intubation. ${ }^{39}$

Numerous laryngoscope blades have been designed to aid with either expected or unanticipated difficult laryngoscopy. Due to unique and varied clinical scenarios as well as inconsistent reporting of variables across studies, direct comparisons of blade performance during difficult laryngoscopy can be problematic. Prisms, mirrors, and other imaging modifications have made indirect laryngoscopy possible with some of the blade choices. Alternative techniques, as well as fiberoptic and videobased technologies, have also led some laryngoscope blade designs to be a matter of historic interest only. Nonetheless, alternative blades may have distinctive designs to facilitate difficult laryngoscopy (Table 1) or minor modifications to aid in tracheal tube placement. For instance, modified straight blades include the Wisconsin and the Guedel, which have higher flange heights compared with the traditional Miller blade. For this reason, they may provide better laryngeal visualization with greater ease in tracheal tube passage.

\section{Indirect Laryngoscopy}

Despite high success rates, traditional direct laryngoscopic techniques are limited by the direct line-of-sight approach and the requirement that the laryngoscopist visualize beyond the tip of a laryngoscope blade for successful laryngeal visualization. This problem has led to the development of a variety of devices: laryngoscope blade modifications such as the addition of prisms and mirrors, airway adjuncts including stylets and introducers, and a variety of modalities with fiberoptic and video technology.

Endotracheal introducers can be inserted semi-blindly into the trachea; subsequent tracheal intubation can be accomplished by advancing a tracheal tube over this device. Advances in fiberoptic and video technologies have led to the development of a large number of devices that can be used to facilitate airway management in cases in which direct laryngoscopy is difficult or impossible. An indirect view of the glottis may be obtained using a variety of these instruments (Table 2).

A comprehensive examination of each of these technologies is beyond the scope of this review. Indirect laryngoscopy can be performed by obtaining an image of the glottic opening in 2 ways: (1) transmission through a fiberoptic bundle or a system of prisms such as the Airtraq laryngoscope (Prodol Meditec SA, Vizcaya, Spain) to a lens viewed by the operator or a video system or (2) a video camera known as the charge-coupled device that transmits a digital image to a monitor screen that is either integrated like the McGrath Series 5 (Aircraft Medical, Edinburgh, United Kingdom) or one that is stand-alone such as the GlideScope (Verathon, Bothell, Washington).

\section{Optical Stylets}

One of the relatively recent indirect laryngoscopic technologies developed is the optical stylet, a term reported in 1979 to describe a straight rigid endoscope (with an optical eyepiece) that is used as a tracheal tube stylet during intubation. ${ }^{41,42}$ Incorporating fiberoptic imaging elements in the design of intubating stylets has led to improved function and appeal. More than a dozen of these devices have been introduced since $1995 .{ }^{43}$ Bonfils $^{33}$ modified the early rigid and straight design feature by applying a fixed curve to the distal end. Intubating stylets may be either malleable (Shikani optical stylet, Clarus Medical, Minneapolis, Minnesota) or rigid (Bonfils intubation fiberscope, Karl Storz Endoscopy, Tuttlingen, Germany). Both types are very maneuverable, have a mouth-opening requirement only as wide as a tracheal tube itself, and have the 


\section{DiRECT AND INDIRECT LARYNGOSCOPY}
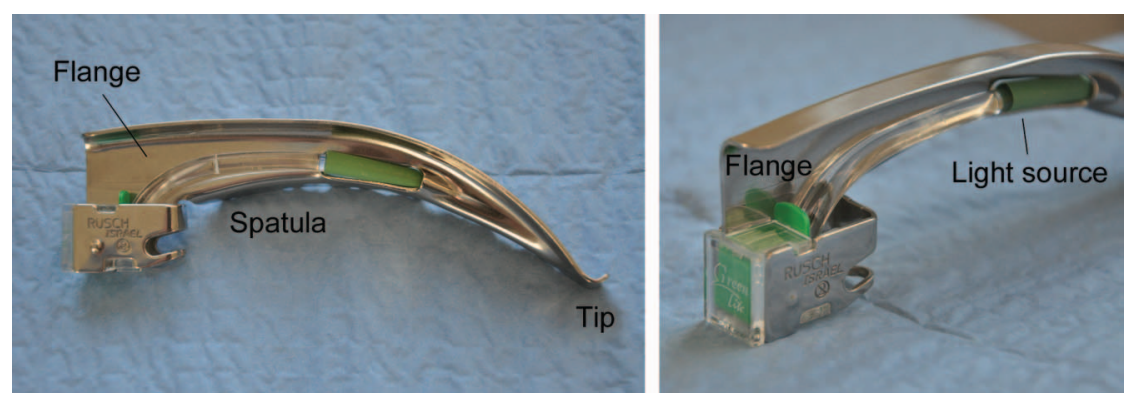

Fig. 7. A curved Macintosh blade illustrating the components of a laryngoscope blade. Of note, the flange is the portion of the blade that projects from the edge of the spatula. Flange height and shape may vary significantly with blade choice (from flat, to slightly curved, to a completely closed tube in some straight blade designs).

Table 1. Selected Laryngoscope Blades

\begin{tabular}{lll}
\hline \hline \multicolumn{1}{c}{ Blade } & \multicolumn{1}{c}{ Characteristics } \\
\hline Macintosh & Curved blade & \multicolumn{1}{c}{ Uses/Advantages } \\
Miller & Straight with curved tip & Most commonly used curved blade; normal airway \\
McCoy or CLM levering & Macintosh design & Normal airway; large floppy epiglottis \\
Wisconsin, Guedel & Straight blades & Articulating distal tip; improves epiglottis lift \\
Belscope & Double-angle blade, prism attachment & Higher flange height; easier to pass tracheal tube \\
Siker & Angled blade & Normal airway; improved glottic view; minimizes dental contact \\
& & Mirrored surface to reflect anterior glottic structures \\
CLM $=$ Corazelli-London-McCoy blade & & \\
\hline
\end{tabular}

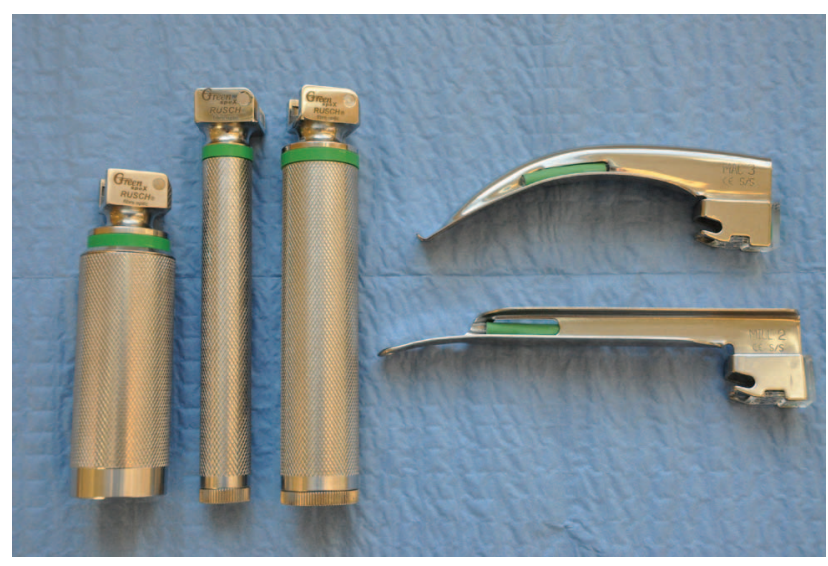

Fig. 8. The curved Macintosh blade and straight Miller blade in standard adult sizes (Macintosh size 3, Miller size 2), with different handle choices available. From left to right: short, pediatric, and standard handle sizes. Each blade comes in a variety of sizes from infant to large adult.

capacity for tracheoscopy. Reports suggest that the learning curve requires $\sim 20$ uses, ${ }^{44}$ and the devices are easily adapted and used by practitioners already skilled with flexible fiberoptic technology.

\section{Rigid Fiberoptic Laryngoscopes}

Similar to optical stylets, indirect rigid fiberoptic laryngoscopes provide a non-line-of-sight view of the glottic
Table 2. Indirect Laryngoscopic Techniques

\author{
Optical stylets \\ Malleable (Levitan, Shikani) \\ Rigid (Bonfils) \\ Rigid laryngoscopes \\ With a tracheal tube guide: WuScope, UpsherScope, Bullard \\ Without a tracheal tube guide: GlideScope, McGrath, Storz \\ Flexible laryngoscopes (flexible fiberoptic bronchoscope)
}

Adapted from Reference 40

aperture. They were designed to facilitate intubation and offer the advantage of visual control of tracheal tube advancement. The Bullard laryngoscope (ACMI Corp, Norwalk, Ohio) was introduced in 1988. It has a dedicated intubating stylet and a working channel that can be used to instill local anesthesia or insufflate oxygen. Its main distinguishing feature is a blade thickness of only $6 \mathrm{~mm}$, which facilitates intubation in patients with limited mouth opening. A midline approach is used when inserting the Bullard laryngoscope, which is advanced and rotated around the base of the tongue during insertion and designed to lift the epiglottis by a tongue pull or jaw thrust. Once the tracheal tube is advanced off the stylet, only minor adjustments are possible. The Bullard laryngoscope has been used successfully to place double-lumen endotracheal tubes, ${ }^{45}$ in cervical spine injury patient models using in- 


\section{DIRECT AND INDIRECT LARYNGOSCOPY}

line stabilization, ${ }^{46,47}$ in patients with suspected cervical spine injuries ${ }^{48}$ in routine airway management, ${ }^{49}$ in anticipated difficult laryngoscopy, ${ }^{50}$ and in unexpected difficult intubations. ${ }^{51}$ It has been demonstrated in immobilized cervical spine simulators using naïve operators to be an easily mastered airway management device based on success, time, and ease of intubation. ${ }^{52}$ Competence has also been shown with the Bullard laryngoscope after a selflearning course and mannequin practice only..$^{53}$

The WuScope (Achi Corp, Fremont, California) and the UpsherScope (Mercury Medical, Clearwater, Florida) were subsequently introduced following the Bullard laryngoscope; however, they have recently been withdrawn from the market. Another rigid laryngoscope, the TruView EVO2 (Truphatek, Netanya, Israel), has a dedicated digital camera that attaches to an optical viewport. Several studies have shown that this device produces superior laryngeal views and requires less force during laryngoscopy compared with a Macintosh laryngoscope blade. ${ }^{54,55}$ Like other rigid fiberoptic laryngoscopes, it is robust and easily portable and can control soft tissue well during laryngoscopy. However, these devices have not gained widespread use in clinical practice. They lack the versatility of flexible fiberoptic bronchoscopes or the more familiar and easy-touse video laryngoscope devices. In fact, although several of the rigid fiberoptic laryngoscopes retain a place in clinical practice for airway management and intubation, many have been eclipsed by the use of newer video laryngoscopes described in more detail below.

\section{Rigid Video Laryngoscopes}

Video laryngoscopes resemble traditional laryngoscopes but have a small video chip embedded in their blades to provide laryngeal views for intubation. Video-assisted laryngoscopy may provide a superior view of the larynx compared with direct line-of-sight laryngoscopy. ${ }^{56}$ The devices are often used as a first-line tool in anticipated difficult laryngoscopy or in attempts to rescue difficult (and unsuccessful) direct laryngoscopic intubations. Their increasing availability and use highlight their promise as new tools for airway management and intubation.

With the exception of the Airtraq (an optical laryngoscope in which an image is generated by a series of optical lenses and prisms), video laryngoscopes use video camera technology focused at the laryngeal inlet to capture an image close to the vocal cords. The image is displayed on a screen that is either attached to the laryngoscope itself or displayed on a remote screen. Video laryngoscopes have gained widespread use, and many of the devices have short and steep learning curves for novice trainees. They are robust, easy to use, and require minimal setup time. Some are channeled devices whereby the laryngoscope and tracheal tube move as a single unit; others are non-channeled devices whereby the tracheal tube and laryngoscope are independently maneuvered typically by use of a stylet. Most have the ability to capture time-annotated images during laryngoscopy, which can be beneficial for clinical documentation and education and teaching purposes.

Numerous video laryngoscopes are commercially available and have been comprehensively reviewed elsewhere. ${ }^{57}$ Table 3 lists and describes various features of some of the more recently developed video laryngoscopes. These include the GlideScope, Pentax AWS100 (AirWay Scope, Pentax Corp, Tokyo, Japan), McGrath Series 5, CoPilot (Magaw Medical, Fort Worth, Texas), and the Storz DCI (Karl Storz, Tuttlingen, Germany) and its successors, the V-MAC and C-MAC. Figures 9 and 10 highlight representative video laryngoscopes. Some, like the V-MAC and C-MAC, have a blade shape based on the standard Macintosh laryngoscope and offer a familiar technique to those trained in direct laryngoscopy. The glottis can be visualized by direct vision or on a video screen. Other video laryngoscopes (GlideScope, McGrath Series 5, CoPilot) have an angulated blade with a sharper curve than seen with the Macintosh blade. Direct visualization is not usually possible, but the glottic opening can be viewed on a video screen with minimal cervical flexion or extension.

The laryngoscope blade is introduced in the midline of the oral cavity without displacing the tongue and then advanced beyond the tongue base until the blade reaches the vallecula or a position posterior to the epiglottis if the epiglottis obstructs the glottic opening. This technique holds true with tube channel-type video laryngoscopes like the Pentax AWS100 and Airtraq as well. With this type of design, the endotracheal tube is preloaded into a guide channel, which facilitates insertion.

Some authors advocate subluxing the temporomandibular joint using a jaw thrust to insert the device along the palate and posterior pharynx rather than alongside the tongue. ${ }^{58}$ Others have recommended passing the tracheal tube under direct vision prior to placement of the instrument. ${ }^{59}$ Using a video laryngoscope, superior views of the glottis are often obtained; however, this improved view may not consistently translate into an easier tracheal intubation. ${ }^{60,61}$ This may be due to several factors, including the sharp anterior deflection of many video laryngoscope blades, which may yield an optimal view of the vocal cords but may not enable easy manipulation and passage of a tracheal tube while viewing an attached monitor.

A unique problem encountered with many video laryngoscopes is the blind spot created as the endotracheal tube is advanced across the oropharynx, where it cannot be visualized by the operator on the display screen. Advancing the tube blindly until it comes into view on the screen has resulted in trauma to the oropharynx in some reported cases. ${ }^{62,63}$ Newer designs, including the CoPilot (Fig. 10), utilize guide channels to facilitate tracheal tube insertion. 


\section{DIRECT AND INDIRECT LARYNGOSCOPY}

Table 3. Selected Video Laryngoscopes

\begin{tabular}{|c|c|}
\hline Name & Special Features \\
\hline Airtraq optical laryngoscope & $\begin{array}{l}\text { Single-use, battery-powered; reusable optic piece; prisms and fog-resistant lenses transmit image; } \\
\text { attachable proprietary camera; built-in channel to guide endotracheal tube }\end{array}$ \\
\hline GlideScope video laryngoscope & $\begin{array}{l}\text { High-resolution video camera housed within laryngoscope blade; color monitor with DVD clarity; } \\
\text { disposable and reusable blades; facilitates intubation in routine and difficult laryngoscopies }\end{array}$ \\
\hline GlideScope Ranger & $\begin{array}{l}\text { Self-contained portable unit with rechargeable battery; rugged and compact; designed for EMS and } \\
\text { military paramedics (pre-hospital use) }\end{array}$ \\
\hline GlideScope AVL & Third-generation battery-powered GlideScope; high-resolution screen with recording capability \\
\hline Pentax AirWay Scope & $\begin{array}{l}\text { High-resolution image; small screen swivels in a single plane; superimposed crosshairs upon display } \\
\text { to direct endotracheal tube; midline channel for suction, oxygen insufflation, or instillation of } \\
\text { topical anesthetic; one size only }\end{array}$ \\
\hline McGrath Series 5 & $\begin{array}{l}\text { Adjustable-length, single-use blade; viewing monitor located on handle containing disposable } \\
\text { battery; monitor can be tilted and swiveled in a } 90^{\circ} \text { arc to optimize view }\end{array}$ \\
\hline Storz DCI & $\begin{array}{l}\text { Interchangeable laryngoscope blades that can be used directly or indirectly (on the monitor); V-MAC } \\
\text { is successor with proprietary monitor, processor, and light source; another successor, the C-MAC, } \\
\text { employs video chip technology }\end{array}$ \\
\hline CoPilot & $\begin{array}{l}\text { Lightweight handle and blade with small viewing screen; angulated blade with bougie port channel } \\
\text { to facilitate endotracheal tube passage }\end{array}$ \\
\hline $\begin{array}{l}\mathrm{DVD}=\text { digital video disc } \\
\mathrm{EMS}=\text { emergency medical services } \\
\mathrm{AVL}=\text { advanced video laryngoscope }\end{array}$ & \\
\hline
\end{tabular}

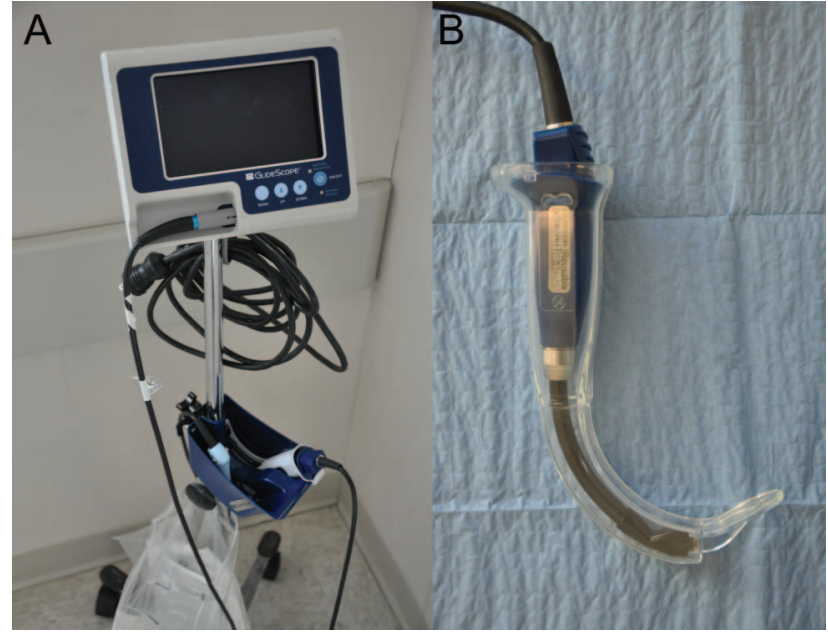

Fig. 9. A: The GlideScope with attached monitor. The generation GlideScope pictured lacks image capture or recording capability, features that are available in other models. Robust plastic blades range in size from pediatric to large adult. B: An adult blade (size 3) loaded over the GlideScope. Note the blade resembles the Macintosh blade except that it has more anterior curve at the distal third.

In addition, specific manufacturer-specific stylets have been recommended, ${ }^{64}$ as well as specific tracheal tubes. ${ }^{65}$

Although their role in airway management has yet to be fully determined, video laryngoscopes have been advocated for use in routine and difficult airways. ${ }^{57}$ Improved intubation success rates may be seen in particular in difficult airway scenarios. Case reports, ${ }^{66}$ case series, ${ }^{67-69}$ and larger retrospective studies ${ }^{60}$ have provided evidence that

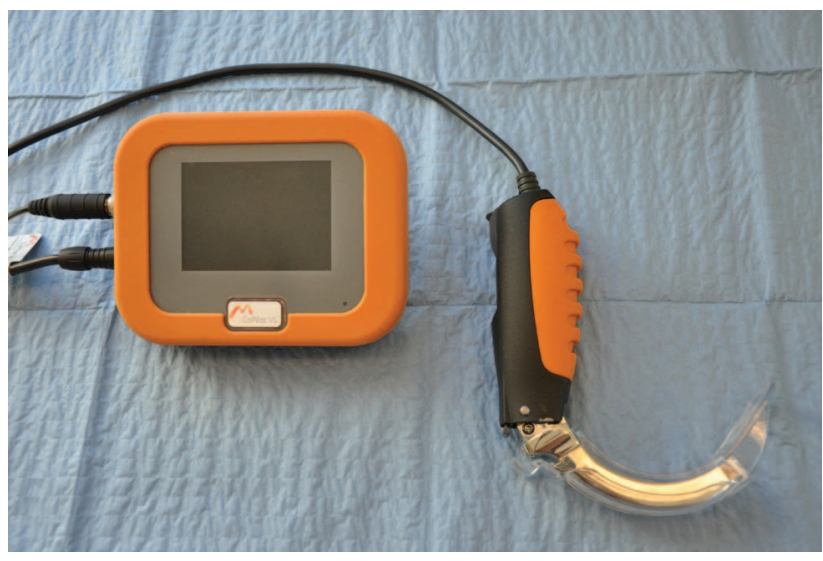

Fig. 10. The CoPilot. Like the GlideScope, this video laryngoscope has an angulated blade to facilitate clear image capture of the glottic opening. The CoPilot offers a specialized C-shaped bougie port channel running alongside the laryngoscope blade, which allows for placement of a bougie through the cords. As an endotracheal tube is passed over the bougie, the bougie is then dislodged from the channel, thereby facilitating tube placement.

video laryngoscopes are useful as rescue devices after failed direct laryngoscopy. In one large retrospective study of $>2,000$ intubations, ${ }^{60}$ subjects were identified as potential difficult laryngoscopic intubations if they had limited mouth opening $(<3 \mathrm{~cm})$ or short thyromental distance $(<6 \mathrm{~cm})$, pre-existing neck pathology (mass, surgical scar, or radiation), a Mallampati score of 3 or 4, or limited neck extension or were morbidly obese. As a primary device, the GlideScope was successful in $98 \%$ of cases and in $94 \%$ of cases of failed direct laryngoscopy. Similar findings have 


\section{DIRECT AND INDIRECT LARYNGOSCOPY}

been reported using other video laryngoscopes in smaller retrospective studies in difficult-to-intubate patients by direct laryngoscopy. ${ }^{70-72}$

One recent study demonstrated that use of a GlideScope by less experienced operators (Pulmonary and Critical Care Medicine fellows) resulted in better first-attempt intubation success rates with fewer complications (compared with a traditional straight or curved blade) when performed for urgent endotracheal intubations in the critically ill. ${ }^{73}$ However, another recent trial of 623 consecutive trauma subjects requiring emergent airway management reported no differences in first-pass success and longer intubation times with use of the GlideScope. ${ }^{74}$ In addition, one subgroup of severe head injury trauma subjects in the video laryngoscope cohort also experienced a greater incidence of hypoxia of $80 \%$ or less $(50 \%$ vs $24 \%$ ).

One important advantage of video laryngoscopes is the shared view between teacher and trainee that is precluded by direct approach techniques. This feature may lead to improved proficiency and acquisition of skills, as trainee technique can be evaluated during the intubation process. In one prospective crossover trial using the C-MAC video laryngoscope, novices were successful in $69 \%$ of intubation attempts during video-assisted instruction, whereas $55 \%$ were successful using traditional laryngoscopic instruction. Novice trainees may be better able to identify and appreciate anatomic structures with video imaging and use of a monitor with a magnified image, ${ }^{75}$ which may hasten skill acquisition. ${ }^{76}$ It is possible that many of the video laryngoscopes have short and steep learning curves for this reason.

One study has estimated that the learning curve to achieve proficiency with the GlideScope by inexperienced users is 8 patients. ${ }^{77}$ Similar findings were reported with the Airtraq optical laryngoscope ${ }^{78,79}$ using difficult intubation models, as well as with the Airtraq ${ }^{80}$ and Pentax AWS ${ }^{81}$ in patients with normal-appearing airways. Multiple-comparison studies between the Macintosh laryngoscope and various video laryngoscopes in mannequin studies also show evidence that intubation skills with the new devices are rapidly mastered and that video laryngoscopes provide superior laryngeal views, although intubation times may be longer. ${ }^{82-87}$

A recent randomized controlled trial in consecutive surgical subjects found that the Airtraq laryngoscope facilitated a more rapid learning curve compared with the Macintosh laryngoscope when used by first-year residents and that the device was judged easier to use. ${ }^{88}$ In contrast, statistical modeling studies based on at least one longitudinal study of novices have shown that a $90 \%$ probability of a good intubation, signifying competence, requires 47 attempts by direct laryngoscopic methods. ${ }^{89}$

A large number of studies exist comparing various video laryngoscopes and direct laryngoscopic methods using the
Macintosh laryngoscope based on a variety of elements in the intubation process. These include intubation time, glottis visualization, and ease of intubation using composite scoring systems. ${ }^{20}$ Comparative studies of direct laryngoscopic methods and video laryngoscope approaches are difficult to interpret for this reason. In one representative study, use of the GlideScope led to an improved laryngeal view (94.4\%) compared with the Storz DCI (63.8\%, $P<.001)$ in 120 adult subjects with at least one predictive feature of a difficult laryngoscopy. ${ }^{90}$ Of this group, the number of subjects who could not be intubated within 2 attempts was one using the GlideScope, one with the Storz DCI, and 4 with a standard Macintosh laryngoscope. Some have argued that the view (Cormack-Lehane) obtained by direct laryngoscopy is not statistically comparable at all with that obtained using video laryngoscopy. ${ }^{91}$

During direct laryngoscopy, a restricted view may be present due to the distance between the object (glottic opening) and the viewer (laryngoscopist) as well as the angle of view $\left(15-30^{\circ}\right)$. During video laryngoscopy, a camera or viewing lens is near the tip of the laryngoscope blade with an angle of view of $\sim 50-60^{\circ} .{ }^{92}$ Moreover, with video laryngoscopes, the image obtained from a camera is at a variable distance from the tip of the blade. For instance, it is $5.5 \mathrm{~cm}$ from the tip in a size 4 GlideScope, $3.5 \mathrm{~cm}$ using the C-MAC, and $\sim 3 \mathrm{~cm}$ using the Pentax AirWay Scope.${ }^{91}$ Finally, an improved view of the larynx may not equate with successful or ease of intubation. For example, in one study with 722 adult subjects, half of the failed intubations $(3.7 \%)$ occurred despite a good or excellent view using the GlideScope. ${ }^{93}$ Given these considerations, the Cormack-Lehane (laryngeal) grading of direct laryngoscopy is probably not an ideal or comparable end point.

Due to the variety of definitions and end points in defining intubation methods and laryngoscopy difficulty and failure, current comparative evidence among these devices remains limited. Various evaluation tools will need to be continually advanced to address how new devices perform in clinical practice. One large meta-analysis ${ }^{94}$ involving over 6,000 subjects evaluated novel intubation devices and reported that there is insufficient evidence to support the use of such alternative devices over standard direct laryngoscopy in routine or difficult intubation. The authors noted that the comparative data from multiple studies were limited, highly heterogeneous with differing end points, and inadequate for comparison between devices or versus the standard Macintosh laryngoscope.

\section{Summary}

Laryngoscopy is the primary means for placing a endotracheal tube during airway management in a variety of clinical settings. Direct laryngoscopic techniques remain a 


\section{DIRECT AND INDIRECT LARYNGOSCOPY}

fundamental approach in routine as well as difficult intubations. More recently, a variety of devices and technologies have been developed to aid as intubation tools. Indirect laryngoscopic methods include rigid fiberoptic laryngoscopy and rigid video laryngoscopy, both of which are potentially useful modalities for management of the difficult airway and may bridge a gap between direct laryngoscopy and other established techniques such as flexible fiberoptic intubation. Video laryngoscopes have recently been added to the practice guidelines by the American Society of Anesthesiologists for management of the difficult airway. ${ }^{9}$ Although their role and range during airway management are not well defined and remain evidence-limited, they are promising devices for routine clinical practice, as rescue tools after failed laryngoscopy, and in airway teaching and training.

\section{REFERENCES}

1. Jahn A, Blitzer A. A short history of laryngoscopy. Logoped Phoniatr Vocol 1996;21(3-4):181-185.

2. Green H. In Green H, editor: On the surgical treatment of polypi of the larynx, and oedema of the glottis. New York: GP Putnam; 1852; 46-65.

3. Janeway HH. Intra-tracheal anesthesia from the standpoint of the nose, throat, and oral surgeon with a description of a new instrument for catheterizing the trachea. Laryngoscope 1913;23(11):1082-1090.

4. Miller RA. A new laryngoscope. Anesthesiology 1941;2(3):317-320.

5. Macintosh RR. New inventions: a new laryngoscope. Lancet 1943; 1(6):205.

6. Heidegger T, Gerig HJ, Ulrich B, Kreienbühl G. Validation of a simple algorithm for tracheal intubation: daily practice is the key to success in emergencies-an analysis of 13,248 intubations. Anesth Analg 2001;92(2):517-522.

7. Levitan RM, Rosenblatt B, Meiner EM, Reilly PM, Hollander JE. Alternating day emergency medicine and anesthesia resident responsibility for management of the trauma airway: a study of laryngoscopy performance and intubation success. Ann Emerg Med 2004; 43(1):48-53.

8. Adnet F, Racine SX, Borron SW, Clemessy JL, Fournier JL, Lapostolle F, Cupa M. A survey of tracheal intubation difficulty in the operating room: a prospective observational study. Acta Anaesthesiol Scand 2001;45(3):327-332.

9. Apfelbaum JL, Hagberg CA, Caplan RA, Blitt CD, Connis RT, Nickinovich DG, et al. Practice Guidelines for Management of the Difficult Airway: an updated report by the American Society of Anesthesiologists Task Force on Management of the Difficult Airway. Anesthesiology 2013;118(2):251-270.

10. Greenland KB. Airway assessment based on a three column model of direct laryngoscopy. Anaesth Intensive Care 2010;38(1):14-19.

11. Tsuiki S, Isono S, Ishikawa T, Yamashiro Y, Tatsumi K, Nishino T. Anatomical balance of the upper airway and obstructive sleep apnea. Anesthesiology 2008;108(6):1009-1015.

12. Cormack RS, Lehane J. Difficult tracheal intubation in obstetrics. Anaesthesia 1984;39(11):1105-1111.

13. Yentis SM. Predicting trouble in airway management. Anesthesiology 2006;105(5):871-872.

14. Shiga T, Wajima Z, Inoue T, Sakamoto A. Predicting difficult intubation in apparently normal patients: a meta-analysis of bedside screening test performance. Anesthesiology 2005;103(2):429-437.

15. Yentis SM. Predicting difficult intubation: worthwhile exercise or pointless ritual? Anaesthesia 2002;57(2):105-109.
16. Samsoon GL, Young JR. Difficult tracheal intubation: a retrospective study. Anaesthesia 1987;42(5):487-490.

17. Mashour GA, Sandberg WS. Craniocervical extension improves the specificity and predictive value of the Mallampati airway evaluation. Anesth Analg 2006;103(5):1256-1259.

18. Lee A, Fan LT, Gin T, Karmakar MK, Kee W. A systematic review (meta-analysis) of the accuracy of the Mallampati tests to predict the difficult airway. Anesth Analg 2006;102(6):1867-1878.

19. Khan ZH, Kashfi A, Ebrahimkhani E. A comparison of the upper lip bite test (a simple new technique) with modified Mallampati classification in predicting difficulty in endotracheal intubation: a prospective blinded study. Anesth Analg 2003;96(2):595-599.

20. Adnet F, Borron SW, Racine SX, Clemessy JL, Fournier JL, Plaisance $\mathrm{P}$, Lapandry $\mathrm{C}$. The intubation difficulty scale (IDS): proposal and evaluation of a new score characterizing the complexity of endotracheal intubation. Anesthesiology 1997;87(6):1290-1297.

21. el-Ganzouri AR, McCarthy RJ, Tuman KJ, Tanck EN, Ivankovich AD. Preoperative airway assessment: predictive value of a multivariate risk index. Anesth Analg 1996;82(6):1197-1204.

22. Knill RL. Difficult laryngoscopy made easy with a BURP. Can J Anaesth 1993;40(3):279-282.

23. Takahata O, Kubota M, Mamiya K, Akama Y, Nozaka T, Matsumoto H, Ogawa H. The efficacy of the "BURP" maneuver during a difficult laryngoscopy. Anesth Analg 1997;84(2):419-421.

24. Levitan RM, Kinkle WC, Levin WJ, Everett WW. Laryngeal view during laryngoscopy: a randomized trial comparing cricoid pressure, backward-upward-rightward pressure, and bimanual laryngoscopy. Ann Emerg Med 2006;47(6):548-555.

25. Mace SE. Challenges and advances in intubation: airway evaluation and controversies with intubation. Emerg Med Clin North Am 2008; 25(4):977-1000.

26. Greenland KB, Eley V, Edwards MJ, Allen P, Irwin MG. The origins of the sniffing position and the three axes alignment theory for direct laryngoscopy. Anaesth Intensive Care 2008;36(Suppl 1):23-27.

27. Adnet F, Borron SW, Lapostolle F, Lapandry C. The three axis alignment theory and the "sniffing position": perpetuation of an anatomic myth? Anesthesiology 1999;91(6):1964-1965.

28. Adnet F, Borron SW, Dumas JL, Lapostolle F, Cupa M, Lapandry C. Study of the "sniffing position" by magnetic resonance imaging. Anesthesiology 2001;94(1):83-86.

29. Adnet F, Baillard C, Borron SW, Denantes C, Lefebvre L, Galinski M, et al. Randomized study comparing the "sniffing position" with simple head extension for laryngoscopic view in elective surgery patients. Anesthesiology 2001;95(4):836-841.

30. Collins JS, Lemmens HJ, Brodsky JB, Brock-Utne JG, Levitan RM. Laryngoscopy and morbid obesity: a comparison of the "sniff" and "ramped" positions. Obes Surg 2004;14(9):1171-1175.

31. El-Orbany M, Woehlck H, Salem MR. Head and neck position for direct laryngoscopy. Anesth Analg 2011;113(1):103-109.

32. Henderson JJ. The use of paraglossal straight blade laryngoscopy in difficult tracheal intubation. Anaesthesia 1997;52(6):552-560.

33. Bonfils P. [Difficult intubation in Pierre-Robin children, a new method: the retromolar route]. Anaesthetist 1983;32(7):363-367. Article in German.

34. Agrawal S, Asthana V, Meher R, Singh DK. Paraglossal straight blade intubation technique; an old technique revisited in difficult intubations: a series of 5 cases. Indian J Anaesth 2008;52(3):317-320.

35. Saxena KN, Nischal H, Bhardwaj M, Gaba P, Shastry BV. Right molar approach to tracheal intubation in a child with Pierre Robin syndrome, cleft palate, and tongue tie. Br J Anaesth 2008;100(1): 141-142.

36. Yamamoto K, Tsubokawa T, Ohmura S, Itoh H, Kobayashi T. Leftmolar approach improves the laryngeal view in patients with difficult laryngoscopy. Anesthesiology 2000;92(1):70-74. 


\section{DIRECT AND INDIRECT LARYNGOSCOPY}

37. Campbell W. Rigid laryngoscopes. In: Roberts J, editor. Clinical management of the airway. Philadelphia: WB Saunders Co; 1994: 134-139.

38. Nunnally ME, Hernandez MR. Unanticipated difficult direct laryngoscopy: methods to improve its success. In: Glick DB, Cooper RM, Ovassapian A, editors. The difficult airway: an atlas of tools and techniques for clinical management. New York: Springer; 2013:47-63.

39. Arino JJ, Velasco JM, Gasco C, Lopez-Timoneda F. Straight blades improve visualization of the larynx while curved blades increase ease of intubation: a comparison of the Macintosh, Miller, McCoy, Belscope and Lee-Fiberview blades. Can J Anaesth 2003;50(5):501-506.

40. Pott LM, Murray WB. Review of video laryngoscopy and rigid fiberoptic laryngoscopy. Curr Opin Anaesthesiol 2008;21:750-758.

41. Berci G, Katz R. Optical stylet: an aid to intubation and teaching. Ann Otol Rhinol Laryngol 1979;88(Pt 1):828-831.

42. Katz RL, Berci G. The optical stylet: a new intubation technique for adults and children with specific reference to teaching. Anesthesiology 1979;51(3):251-254.

43. Liem EB, Bjoraker DG, Gravenstein D. New options for airway management: intubating fibreoptic stylets. Br J Anaesth 2003;91(3): 408-418.

44. Gravenstein D, Liem EB, Bjoraker DG. Alternative management techniques for the difficult airway: optical stylets. Curr Opin Anaesthesiol 2004;17(6):495-498.

45. Shulman GB, Connelly NR. Double lumen tube placement with the Bullard laryngoscope. Can J Anaesth 1999;46(3):232-234.

46. Shulman GB, Connelly NR. A comparison of the Bullard laryngoscope versus the flexible fiberoptic bronchoscope during intubation in patients afforded inline stabilization. J Clin Anesth 2001;13(3): 182-185.

47. Watts AD, Gelb AW, Bach DB, Pelz DM. Comparison of the Bullard and Macintosh laryngoscopes for endotracheal intubation of patients with a potential cervical spine injury. Anesthesiology 1997; 87(6):1335-1342.

48. Abrams KJ, Desai N, Katsnelson T. Bullard laryngoscopy for trauma airway management in suspected cervical spine injuries. Anesth Analg 1992;74(4):623.

49. Cooper SD, Benumof JL, Ozaki GT. Evaluation of the Bullard laryngoscope using the new intubating stylet: comparison with conventional laryngoscopy. Anesth Analg 1994;79(5):965-970.

50. Gorback MS. Management of the challenging airway with the Bullard laryngoscope. J Clin Anesth 1991;3(6):473-477.

51. Connelly NR, Ghandour K, Robbins L, Dunn S, Gibson C. Management of unexpected difficult airway at a teaching institution over a 7-year period. J Clin Anesth 2006;18(3):198-204.

52. Wackett A, Anderson K, Thode H. Bullard laryngoscopy by naïve operators in the cervical spine immobilized patient. J Emerg Med 2005;29(3):253-257.

53. Pott LM, Santrock D. Teaching without a teacher: developing competence with a Bullard laryngoscope using only a structured selflearning course and practicing on a mannequin. J Clin Anesth 2007; 19(8):583-586.

54. Barak M, Philipchuck P, Abecassis P, Katz Y. A comparison of the Truview blade with the Macintosh blade in adult patients. Anaesthesia 2007;62(8):827-831.

55. Li JB, Xiong YC, Wang XL, Fan XH, Li Y, Xu H, et al. An evaluation of the TruView EVO2 laryngoscope. Anaesthesia 2007;62(9): 940-943.

56. Kaplan MB, Hagberg CA, Ward DS, Brambrink A, Chhibber AK, Heidegger $\mathrm{T}$, et al. Comparison of direct and video-assisted views of the larynx during routine intubation. J Clin Anesth 2006;18(5):357-362.

57. Cooper RM, Lee C. Role of rigid video laryngoscopy. In: Glick DB, Cooper RM, Ovassapian A, editors. The difficult airway: an atlas of tools and techniques for clinical management. New York: Springer; 2013:77-111.

58. Henderson JJ, Suzuki A. Rigid indirect laryngoscope insertion techniques. Anaesthesia 2008;63(3):323-324.

59. Neustein S. Advancing the endotracheal tube smoothly when using the GlideScope (letter). Can J Anesth 2008;55(5):314-315.

60. Aziz MF, Healy D, Kheterpal S, Fu RF, Dillman D, Brambrink AM. Routine clinical practice effectiveness of the GlideScope in difficult airway management: an analysis of 2,004 GlideScope intubations, complications and failures from two institutions. Anesthesiology 2011;114(1):34-41.

61. Niforopoulou P, Pantazopoulos I, Demestiha T, Koudouna E, Xanthos T. Video-laryngoscopes in the adult airway management: a topical review of the literature. Acta Anaesthesiol Scand 2010;54(9): 1050-1061.

62. Amundson AW, Weingarten TN. Traumatic GlideScope video laryngoscopy resulting in perforation of the soft palate (letter). Can J Anesth 2013;60(2):210-211.

63. Leong WL, Lim Y, Sia AT. Palatopharyngeal wall perforation during GlideScope intubation. Anaesth Intensive Care 2008;36(6):870874.

64. Neustein S. The GlideScope-specific rigid stylet to facilitate tracheal intubation with the GlideScope (letter). Can J Anesth 2008;55(3): 196-197; author reply 197.

65. Phua D, Wang CF, Yoong CS. Use of the Endoflex endotracheal tube as a stylet-free alternative in GlideScope intubations (letter). Can J Anesth 2008;55(7):473-474.

66. Shippey B, Ray D, McKeown D. Use of the McGrath videolaryngoscope in the management of difficult and failed tracheal intubation. Br J Anaesth 2008;100(1):116-119.

67. Maharaj CH, Costello JF, McDonnell JG, Harte BH, Laffey JG. The Airtraq as a rescue airway device following failed direct laryngoscopy: a case series. Anaesthesia 2007;62(6):598-601.

68. Flores AS, Garber SM, Niesen AD, Long TR, Lynch JJ, Wass CT. Clinical application of a novel video camera laryngoscope: a case series venturing beyond the normal airway. J Clin Anesth 2010; 22(3):201-204

69. Lai HY, Chen IH, Chen A, Hwang FY, Lee Y. The use of the GlideScope for tracheal intubation in patients with ankylosing spondylitis. Br J Anaesth 2006;97(3):419-422.

70. Kurihara R, Inagawa G, Kikuchi T, Koyama Y, Goto T. Airway Scope for difficult intubation. J Clin Anesth 2007;19(3):240-241.

71. Asai T, Liu EH, Matsumoto S, Hirabayashi Y, Seo N, Suzuki A, et al. Use of the Pentax-AWS in 293 patients with difficult airways. Anesthesiology 2009;110(4):898-904.

72. O'Leary AM, Sandison MR, Myneni N, Cirilla DJ, Roberts KW, Deane GD. Preliminary evaluation of a novel videolaryngoscope, the McGrath series 5, in the management of difficult and challenging endotracheal intubation. J Clin Anesth 2008;20(4):320-321.

73. Kory P, Guevarra K, Mathew JP, Hegde A, Mayo PH. The impact of video laryngoscopy use during urgent endotracheal intubation in the critically ill. Anesth Analg 2013;117(1):144-149.

74. Yeatts DJ, Dutton RP, Hu PF, Chang YW, Brown CH, Chen H, et al. Effect of video laryngoscopy on trauma patient survival: a randomized controlled trial. J Trauma Acute Care Surg 2013;75(2):212-219.

75. Kaplan MB, Ward D, Hagberg CA, Berci G, Hagiike M. Seeing is believing: the importance of video laryngoscopy in teaching and in managing the difficult airway. Surg Endosc 2006;20(Suppl 2):S479S483.

76. Howard-Quijano KJ, Huang YM, Matevosian R, Kaplan MB, Steadman RH. Video-assisted instruction improves the success rate for tracheal intubation by novices. Br J Anaesth 2008;101(4):568-572.

77. Rai MR, Dering A, Verghese C. The GlideScope system: a clinical assessment of performance. Anaesthesia 2005;60(1):60-64. 


\section{DIRECT AND INDIRECT LARYNGOSCOPY}

78. Woollard M, Lighton D, Mannion W, Watt J, McCrea C, Johns I, et al. Airtraq vs standard laryngoscopy by student paramedics and experienced prehospital laryngoscopists managing a model of difficult intubation. Anaesthesia 2008;63(1):26-31.

79. Woollard M, Mannion W, Lighton D, Johns I, O'Meara P, Cotton C, Smyth M. Use of the Airtraq laryngoscope in a model of difficult intubation by prehospital providers not previously trained in laryngoscopy. Anaesthesia 2007;62(10):1061-1065.

80. Baciarello M, Zasa M, Manferdini ME, Tosi M, Berti M, Fanelli G. The learning curve for laryngoscopy: Airtraq versus Macintosh laryngoscopes. J Anesth 2012;26(4):516-524.

81. Hirabayashi Y, Seo N. Tracheal intubation by non-anaesthetist physicians using the Airway Scope. Emerg Med J 2007;24(8):572573.

82. Savoldelli GL, Schiffer E, Abegg C, Baeriswyl V, Clergue F, Waeber JL. Learning curves of the GlideScope, the McGrath and the Airtraq laryngoscopes: a manikin study. Eur J Anaesthesiol 2009; 26(7):554-558.

83. Savoldelli GL, Schiffer E, Abegg C, Baeriswyl V, Clergue F, Waeber JL. Comparison of the GlideScope, the McGrath, the Airtraq and the Macintosh laryngoscopes in simulated difficult airways. Anaesthesia 2008;63(12):1358-1364.

84. Liu L, Tanigawa K, Kusunoki S, Tamura T, Ota K, Yamaga S, et al. Tracheal intubation of a difficult airway using Airway Scope, Airtraq, and Macintosh laryngoscope: a comparative manikin study of inexperienced personnel. Anesth Analg 2010;110(4):1049-1055.

85. Malik MA, Hassett P, Carney J, Higgins BD, Harte BH, Laffey JG. A comparison of the GlideScope, Pentax AWS, and Macintosh laryngoscopes when used by novice personnel: a manikin study. Can J Anaesth 2009;56(11):802-811.
86. Kariya T, Inagawa G, Nakamura K, Fujimoto J, Aoi Y, Morita S, Goto T. Evaluation of the Pentax AWS and the Macintosh laryngoscope in difficult intubation: a manikin study. Acta Anaesthesiol Scand 2011;55(2):223-227.

87. McElwain J, Malik MA, Harte BH, Flynn NM, Laffey JG. Comparison of the C-MAC videolaryngoscope with the Macintosh, GlideScope, and Airtraq laryngoscopes in easy and difficult laryngoscopy scenarios in manikins. Anaesthesia 2010;65(5):483-489.

88. Di Marco P, Scattoni L, Spinoglio A, Luzi M, Canneti A, Pietropaoli P, Reale C. Learning curves of the Airtraq and the Macintosh laryngoscopes for tracheal intubation by novice laryngoscopists: a clinical study. Anesth Analg 2011;112(1):122-125.

89. Mulcaster JT, Mills J, Hung OR, MacQuarrie K, Law JA, Pytka S, et al. Laryngoscopic intubation: learning and performance. Anesthesiology 2003;98(1):23-27.

90. Serocki G, Bein B, Scholz J, Dörges V. Management of the predicted difficult airway: a comparison of conventional blade laryngoscopy with video-assisted blade laryngoscopy and the GlideScope. Eur J Anaesthesiol 2010;27(1):24-30.

91. Mines R, Ahmad I. Can you compare the views of videolaryngoscopes to the Macintosh laryngoscope (letter)? Anaesthesia 2011; 66(4):315-316; author reply 316-317.

92. Angadi SP, Frerk C. Videolaryngoscopy and Cormack and Lehane grading. Anaesthesia 2011;66(7):628-629.

93. Cooper RM, Pacey JA, Bishop MJ, McCluskey SA. Early clinical experience with a new video-laryngoscope (GlideScope). Can J Anaesth 2005;52(2):191-198.

94. Mihai R, Blair E, Kay H, Cook TM. A quantitative review and meta-analysis of performance of non-standard laryngoscopes and rigid fibreoptic intubation aids. Anaesthesia 2008;63(7):745-760.

\section{Discussion}

Blank: Stephen, thanks for the excellent talk. I just have a couple of comments. First, the Bullard laryngoscope does not seem to be very commonly used now, at least not in our practice. We used it more frequently before the GlideScope became available. While the Bullard can be a bit clumsy to use, a significant advantage is that it can be used in a patients with very limited mouth opening. Essentially, if the patient's mouth opening can accommodate the endotracheal tube, it can accommodate the Bullard. This is a clear advantage for the Bullard over the GlideScope in this small subset of patients. My other comment relates to video laryngoscopy. As our ability to adequately visualize the glottis in patients with very anterior airways has improved, we are more likely to encounter the scenario in which the tube has to be so flexed anteriorly that it approaches the vocal cords at an almost $90^{\circ}$ angle, making it difficult to intubate the trachea. One technique that works well is to use an endotracheal tube introducer or flexible fiberoptic bronchoscope at this point to intubate the trachea. Once the introducing device has entered the trachea, the endotracheal tube can be railroaded over it.

Collins: Thank you for your comments. I will add that my preference when encountering difficult glottic views during direct laryngoscopy is to try passing a gum elastic bougie. I believe this can often be done successfully, even with a blind attempt, given the curved tip to aid in placement.
Ramachandran: I have a couple of comments. One, when I was first taught about difficult laryngoscopy, my professor said, "You can't stuff $5 \mathrm{~kg}$ of rice in a 3-kg sack"; so if you can't stuff a big tongue into the subglottic tissues, it's going to sort of fall back, and that's a mechanical cause for persistent epiglottic view we often see with true difficult intubations. Not all video laryngoscopes have the mechanical ability to overcome that anatomical shortcoming. So it's counterintuitive, but if you see a persistent epiglottic view, more pressure makes it worse, and persisting to try to get the laryngoscope tip in the vallecula sometimes makes intubation impossible. Pulling the laryngoscope out sometimes helps your view significantly. It's a nuance, and it's difficult to teach now with a video laryngoscope because, most of the time, we 
get a good view. The second thing is that, with video laryngoscope techniques, sometimes it's difficult to intubate despite a really good view. It is easier to place the tube in first, before you introduce the GlideScope, because there's not enough space sometimes with dental crowding. I don't know if you have any experience with that.

Collins: My practice is typically to obtain a view of the cords using the GlideScope prior to introducing an endotracheal tube. If difficulty is encountered due to space considerations, I have occasionally attempted to introduce carefully both the GlideScope and an endotracheal tube together. It can be frustrating to have a great view of the cords but not be able to intubate because of inability to place or pass a tube easily. If I am worried about the airway with traditional methodologies and having trouble with video laryngoscopy, I usually just then go to the fiberoptic approach.

Hurford: Expanding on your statement, when I've had patients with really difficult airways with tumors and things like that, I've used a video laryngoscope not to help me place the endotracheal tube, but to help me place a fiberoptic scope, using the fiberoptic scope either as a stylet or, in rare occasions, as a lighted stylet when I can see nothing. It helps get a lot out of the way, so I can then have a greater chance of success of using a fiberoptic scope to achieve intubation in a very abnormal airway.

Blank: I agree completely. In the next talk, I deleted a few slides on exactly that for the sake of time, but there are some case series out there and a number of case reports that support this approach in very difficult airway scenarios. It may also be a good adjunct for teaching residents because you can actually visualize the glottis as well as the more distal airway and monitor the progress and the tube advancing over the scope.
Davies: I'm just wondering if anybody else has encountered a direct laryngoscopy where the vocal cords are shut tight not due to pharmacologic agents? If so, what did you do?

Collins: It is not as common a scenario in the operating room or with floor or ICU intubations because we use paralytics often. However, if the patient is stable, I think it is reasonable to mask-ventilate and give the patient time. Additional anesthetic can be administered. Alternatively, if a view of the cords is present on laryngoscopy, that view can be suspended if hemodynamics are stable; if the cords are in motion and do open, one can time it well and pass a gum elastic bougie through at the appropriate time. I've had success with this approach, but it has to be done carefully so as not to cause laryngospasm or injure the cords.

Davies: One of the things we did that's worked a couple times is just getting some $\mathrm{O}_{2}$ tubing down and blowing $\mathrm{O}_{2}$ right on the cords. They sometimes react to that.

Collins: The fiberoptic technique of spray as you go (with topical lidocaine) is often helpful in that regard as well.

Hurford: Another alternative is to use a short-acting opioid like remifentanil, which can be successful in opening the cords, and then you don't have the problems of paralytics. The second thing is that one of the tubes you showed, the Parker tube, with its sort of pointy end, is sometimes successful at getting through the cords where a typical tube is not.

Ramachandran: I just wanted to get back to John's [Davies] point, a word of caution, for the vocal cords, as you know, are particularly prone to injury during intubation attempts with laryngospasm. There are 2 ways to treat laryngospasm, with medications or by waiting until the patient gets really hypoxic. I don't recommend the latter. But the management of laryngospasm is really complicated because now you're in, and the vocal cords are closed. Coming out and ventilating the patient may really not be an option with a tight laryngospasm, in which case, you need the airway to be subglottic for you to be able to ventilate the patient's lungs. It's a very unique situation, and it happens particularly in the sick patients, where you can't give medications and you're trying to get the tube in as soon as possible. We don't encounter it as much because a lot of our practice has shifted toward the use of muscle relaxants. But going back to an earlier discussion we had, in one of our units, we had a higher intubation failure rate, and one way we've got around it is to tell them not to paralyze the patients. So the patients are still spontaneously breathing, hopefully, by the time they call for rescue, but that does increase the risk of ending up in the situation above. I don't know what the solution is, other than saying that if you can't intubate and you can't ventilate, you have to get a surgical airway in and, if necessary, through a tracheostomy. But it needs to be done; otherwise, you just end up with poor neurological outcomes.

Branson: We were doing some evaluations of video laryngoscopes for less skilled users, and one of the things we noticed that seemed to be a problem was their inability to perceive depth. Like you said, they could see, they had good visualization, but they didn't intubate more often because of the visualization. I think that was part of it; I don't know if other people have had that same experience; and for clarity, this was on a mannequin.

Collins: That issue has been described some in the literature with video laryngoscopes. Certainly, having good visual-spatial skills is helpful. However, this is not a skill set 
easily learned: mostly practiced. Again, video laryngoscopy is an indirect method of laryngoscopy, and it can be counterintuitive for trainees to be looking at a screen while working to intubate a patient at a different place physically from their line of sight.

Berkow: Yes, video laryngoscopy has been described as a 2-step process, as opposed to direct laryngoscopy, where, if you have a good view of the glottis, most of the time, tube delivery is easy. But with video laryngoscopy, the first step is identifying the glottis and then delivering the tube, and you really have to learn both of those skills separately because it is a different way of tube delivery using depth and video guidance. So, one doesn't necessarily guarantee the other with video laryngoscopy, and I think it's important that, when we train residents and other providers, they understand that concept.

Durbin: I'm guessing that the current generation, who are so good at video games, are better using video laryngoscopy to intubate than I am. Technology changes so fast that even this group may not be able to keep up either. Of course, some of the issues with new devices relate to the individual's learning curve. Mastering any new mechanical process requires a significant investment in practice time, as well as developing and imprinting a different mental image and understanding the relationship of the airway anatomy and the device. This change in task visualization is difficult for all and occurs at different rates in different individuals.

\section{REFERENCE}

1. Apfelbaum JL, Hagberg CA, Caplan RA, Blitt CD, Connis RT, Nickinovich DG, et al. Practice guidelines for the management of the difficult airway: an updated report by the American Society of Anesthesiologists Task Force on Management of the Difficult Airway. Anesthesiology 2013;118(2):251-270.

This article is approved for Continuing Respiratory Care Education credit. For information and to obtain your CRCE

(free to AARC members) visit

www.rcjournal.com 